\title{
Apparent diffusion coefficient of different areas of brain in foetuses with intrauterine growth restriction
}

\author{
Behnaz Moradi ${ }^{1}, 2 A, B, D, E, F$, Zohreh Alibeigi Nezhad ${ }^{2 B, C, F}$, Nazanin Seyed Saadat ${ }^{2 B, C, F}$, Mahboobeh Shirazi ${ }^{3 A, B}$, \\ Ali Borhani2 ${ }^{2, E}$, Mohammad Ali Kazemi2,4 A,B,E
}

'Department of Radiology, Women's Yas Hospital, Tehran University of Medical Sciences, Tehran, Iran

${ }^{2}$ Department of Radiology, Medical Imaging Centre, Imam Khomeini Hospital Complex (IKHC), Tehran University of Medical Sciences, Tehran, Iran ${ }^{3}$ Maternal, Foetal and Neonatal Research Centre, Women's Yas Hospital, Tehran University of Medical Sciences, Tehran, Iran

${ }^{4}$ Department of Radiology, Amiralam Hospital, Tehran University of Medical Sciences, Tehran, Iran

\section{Abstract}

Purpose: This study aimed to compare the apparent diffusion coefficient (ADC) values of different brain areas between two groups of intrauterine growth restricted (IUGR) foetuses and control cases.

\begin{abstract}
Material and methods: A total of 38 foetuses with IUGR and 18 normal control foetuses with similar gestational age were compared using a $3 \mathrm{~T}$ magnetic resonance scanner. IUGR cases included 23 foetuses with clinical severity signs (group A) and 15 foetuses without clinical severity signs (group B). ADC values were measured in different brain regions and compared among groups. Foetuses with structural brain abnormalities were excluded from the study.

Results: All foetuses had normal foetal structural brain anatomy. Head circumference $(\mathrm{HC})<5 \%$ was more common in IUGR group A compared to IUGR group B $(56.5 \%$ vs. $13.3 \%, p<0.0001)$. In comparison to the normal group, the ADC values in IUGR foetuses were significantly lower in cerebellar hemispheres $(\mathrm{CH})\left(1.239 \mathrm{vs} .1 .280 .5 \times 10^{-3} \mathrm{~mm}^{2} / \mathrm{s}\right.$, $p=0.045)$, thalami $\left(1.205 \mathrm{vs} .1 .285 \times 10^{-3} \mathrm{~mm}^{2} / \mathrm{s}, p=0.031\right)$ and caudate nucleus $(\mathrm{CN})\left(1.319 \mathrm{vs} .1 .394 \times 10^{-3} \mathrm{~mm}^{2} / \mathrm{s}\right.$, $p=0.04)$. However, there were no significant differences in ADC values between IUGR subtypes. Among all brain regions, pons had the lowest $\mathrm{ADC}$ values.
\end{abstract}

Conclusions: ADC values of thalami, CN, and $\mathrm{CH}$ were significantly lower in IUGR than control foetuses, while there was no significant difference among IUGR groups. Further studies are needed to evaluate the prognostic value of ADC changes in IUGR foetuses.

Key words: apparent diffusion coefficient, foetus, diffusion-weighted imaging, hypoxia, growth restriction.

\section{Introduction}

Intrauterine growth restriction (IUGR) is the second most common cause of perinatal mortality. Its prevalence among all newborns is reported to be $5-10 \%[1,2]$. It is strongly associated with adverse pregnancy outcomes and an increased likelihood of abnormal long-term neurodevelopmental complications including cerebral palsy, learning disabilities, and behavioural problems $[3,4]$.
Post-mortem examination of IUGR foetuses shows loss of both grey and white matter substructures, including reduced cell number, disorganised cortical structure, and unmyelinated axons with thinner myelin coverage $[5,6]$. Detection of neonates who will develop neurodevelopmental impairment in the future is challenging. Therefore, neurostructural imaging findings such as changes in gyrification, cortical morphometry, connectivity, and metabolism are suggested to have prognostic value [1,6-11].

Correspondence address:

Prof. Mohammad Ali Kazemi, Amiralam Hospital, Tehran University of Medical Sciences, e-mail: Ma-kazemi@sina.tums.ac.ir

Authors' contribution:

A Study design · B Data collection · C Statistical analysis · D Data interpretation · E Manuscript preparation · F Literature search · G Funds collection 
Not only early severe IUGR foetuses will develop impaired neurocognition, but also foetuses with milder, lateonset forms - which are the majority of IUGR cases - can be affected [1].

The adverse neurodevelopmental outcome in IUGR foetuses is mainly the result of placental insufficiency and chronic hypoxia [2,4]. In a clinical setting, to determining the severity of utero-placental insufficiency and hypoxia, these high-risk pregnancies are monitored with various methods including non-stress test, sonographic biophysical profile, and Doppler ultrasound $[2,5,6]$. These assessments should be done to determine the delivery time and protect foetuses from the risks of hypoxia.

Foetal brain magnetic resonance imaging (MRI) is used to provide distinctive information about the structural and functional status of foetuses [12]. Restricted brain growth, delayed brain gyration, or focal ischaemic/ haemorrhagic lesions could be investigated by conventional MRI; however, identifying diffuse ischaemic changes or earlier and subtle injuries remains challenging [4]. Microstructural abnormalities are also not detectable by conventional MR sequences but could be identified by diffusion-weighted MR imaging (DWI) with altered apparent diffusion coefficient (ADC) values [2,4].

Because there are relatively few studies that have investigated the role of DWI in the IUGR foetal brain, this study aims to evaluate the $\mathrm{ADC}$ value differences in various brain regions between IUGR foetuses and normal controls using DW imaging.

\section{Material and methods}

\section{Patient population}

This prospective study was performed in a university teaching hospital between April 2017 and February 2019. The study was approved by the institutional review board (IRB) of Tehran University of Medical Sciences. Written informed consent was obtained from all women who participated in the study.

Gestational age in all foetuses was established based on the first-trimester crown-rump length (CRL) measurement. IUGR was defined as a foetal estimated weight less than the $10^{\text {th }}$ percentile for gestational age according to the reference data and based on ultrasound measurement [13].

The control group was selected from non-IUGR foetuses with similar gestational age, referred for foetal MRI for suspected ventriculomegaly $(n=2)$, duodenal atresia $(n=2)$, oesophageal atresia $(n=1)$, mega cisterna magna $(n=2)$, posterior urethral valve $(n=1)$, macrosomia $(n=1)$, syndactyly $(n=1)$, hemivertebra $(n=2)$, cleft lip and palate $(n=1)$, pulmonary cyst $(n=1)$, and those with normal foetal MRI and normal outcome $(n=4)$.

Exclusion criteria were as follows: multifoetal pregnancy, history of congenital infection, abnormal brain biometry, chromosomal anomalies, or suspected genetic syndrome. Additionally, any structural or brain abnormalities that were detected on ultrasound or conventional MRI sequences and non-diagnostic DWI sequences with blurred ADC maps (due to motion artefact degradation) were also excluded.

Four cases in the IUGR group and two of the control group were excluded according to the degradation of DW image by foetal motion. We also lost three IUGR cases (due to emergent caesarean delivery: two with severe hypoxia, who delivered their babies before MRI examination appointment, and one due to premature rupture of membranes). Eventually, a total of 38 foetuses with IUGR and 18 from the control group with similar gestational weeks (28-38 weeks) were included.

We recorded the foetal gestational age, biometry, and weight at the time of MRI examination as well as birth weight and pregnancy outcome following delivery.

\section{Doppler ultrasound examinations}

All IUGR foetuses underwent Doppler examination by a trans-abdominal convex array transducer with $2-6 \mathrm{MHz}$ frequency (Affiniti 50, General imaging configuration, Philips ultrasound machine, USA) in the same week of MRI examination. Foetal umbilical artery (UA) and middle cerebral artery (MCA) pulsatility index (PI) and the mean bilateral uterine artery (UtA) PI were measured, and values greater than the $95^{\text {th }}$ percentile were considered abnormal. The cerebroplacental ratio was also calculated, and values less than the $5^{\text {th }}$ percentile were considered abnormal according to the reference chart [14]. All Doppler studies were performed in accordance with the International Society of Ultrasound in Obstetrics and Gynaecology (ISUOG) practice guidelines [15]. IUGR cases were subdivided into two study groups: IUGR with severity signs (group A) defined by birth weight less than the third centile and/or abnormal UA or UtA PI and/or abnormal Cerebroplacental ratio $\left(<5^{\text {th }}\right.$ centile), and group $B$ without any of these criteria.

\section{Magnetic resonance imaging protocol}

Foetal MRI was performed using a 3T MR unit General Electric system (GE Healthcare, discovery 750 GEM), with a 16-channel phased-array coil following four hours of maternal fasting. The IUGR group underwent MRI examination within the same week of diagnosis. No foetal or maternal sedation was used during the MR study, and patients were positioned in the left lateral position on the MR scanner table. As part of the foetal MR examination, conventional sequences for all women included $4 \mathrm{~mm}$ single-shot fast spin-echo $\mathrm{T} 2$-weighted sequences in three orthogonal planes and axial fast multiplanar spoiled gradient-recalled acquisition in the steady-state T1-weighted sequences in an axial plane. Only T1-weighted sequences were performed with breath-holding. 

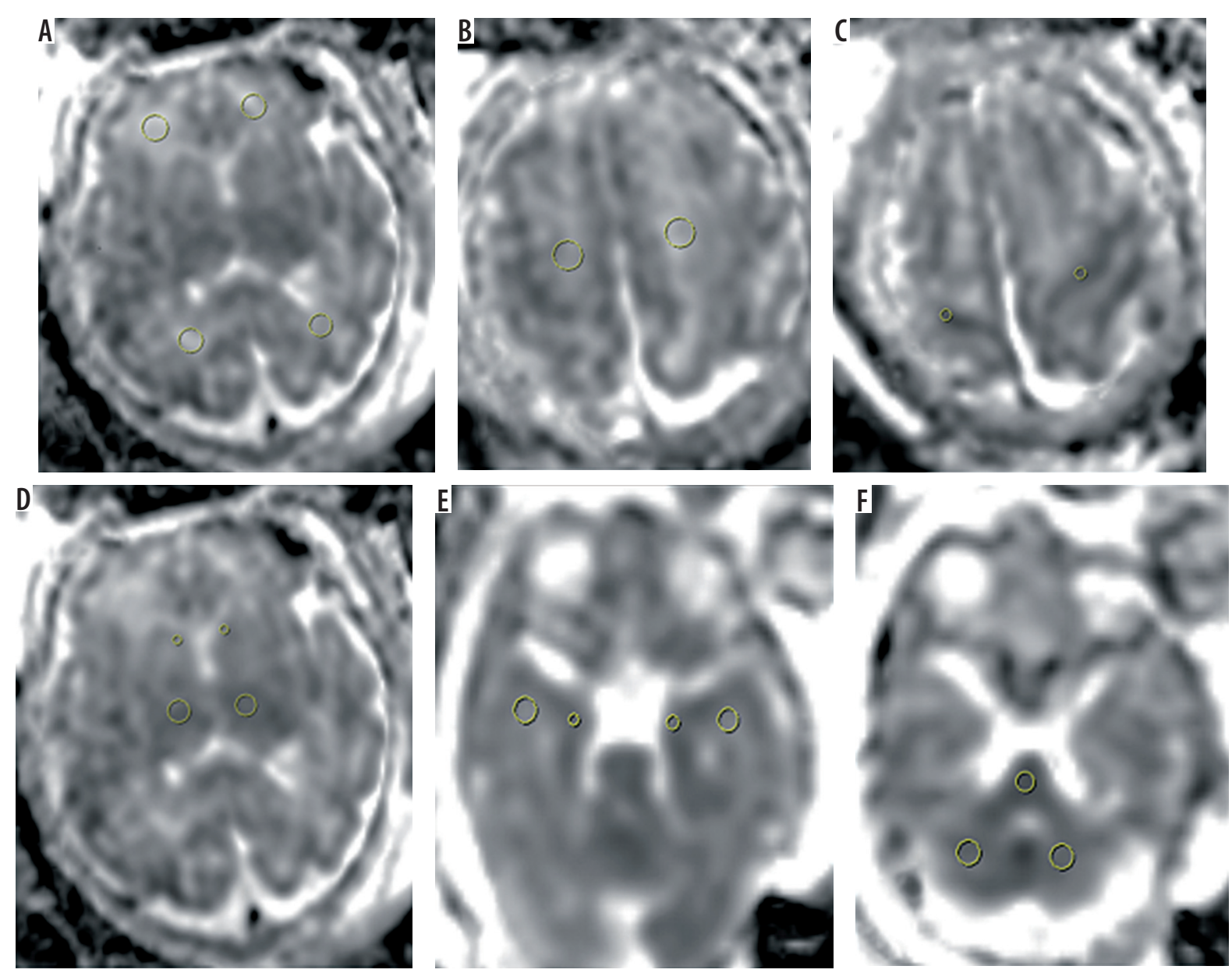

Figure 1. Localisation of the regions of interest (ROIs) within all brain regions. A) Frontal white matter and occipital white matter, B) centrum semi-ovale, C) Rolandic cortex, D) thalami and caudate nucleus, E) temporal lobe white matter and hippocampal cortex and f) pons and cerebellar hemispheres

Foetal brain DWI $\left[\mathrm{b}\right.$ value $=0-700 \mathrm{~s} / \mathrm{mm}^{2}$ in three orthogonal directions] was performed using single-shot spinecho-planar imaging (EPI) in an axial plane without breathholding [TR, 3000 ms; TE, min; FOV, 320-400 mm; matrix, $128 \times 128$; section thickness, $4-5 \mathrm{~mm}$; space, $1 \mathrm{~mm}$; and band-width, $250 \mathrm{kHz}$; acquisition time, $20 \mathrm{~s}$ ]. If any motion artefacts or any distortion were detected, the sequence was repeated until a satisfactory image was obtained; however, we excluded four cases from the IUGR group and two cases from the control group due to the poor quality of the DWI images. ADC mapping was performed on a picture archiving and communication system (PACS). The total mean examination time was $30 \pm 5$ min per patient.

\section{Magnetic resonance imaging analysis}

\section{Conventional sequences}

Brain morphology and signal were assessed by a faculty member radiologist (B.M.: the first author) with five years' experience in foetal imaging and foetal brain MRI. Brain biometry (biparietal diameter [BPD] and head circumference $[\mathrm{HC}]$ ) was assessed according to the reference chart [13]. The reader was aware of the preliminary diagnosis of IUGR but not the subtype.

\section{Diffusion-weighted magnetic resonance imaging sequences}

Multiple circular surfaces, $30-60 \mathrm{~mm}$ regions of interest (ROI), were drawn in different brain regions and plotted on ADC maps by the same radiologist. ROIs were drawn in the frontal white matter (FWM), occipital white matter (OWM), centrum semi-ovale (CSO), thalami, cerebellar hemispheres $(\mathrm{CH})$, and Pons according to the criteria described in previous studies $[4,16]$. Also, we evaluated other regions according to the following criteria (Figure 1):

- temporal lobe white matter (TWM): in the middle of the white matter of the temporal lobe on the axial slice at the level of the midbrain (ROI: 30 to $60 \mathrm{~mm}^{2}$ ),

- hippocampal cortex (HC): at the same level described above, in the grey matter of the hippocampus (ROI: 5-15 $\mathrm{mm}^{2}$ ),

- Rolandic cortex (RC): at the uppermost cut on the axial slice on the Rolandic cortex (ROI: $5 \mathrm{~mm}^{2}$ ),

- caudate nucleus $(\mathrm{CN})$ : in the middle of each caudate nucleus on the axial slice at the level of frontal horn and cavum septum (ROI: $5 \mathrm{~mm}^{2}$ ).

ROI size varied according to the gestational age and size of the foetal brain region of interest. Adjacent structures such as CSF spaces were avoided. All measurements were performed on a PACS workstation. The automati- 
Table 1. Maternal and foetal characteristics of the study groups and perinatal outcome

\begin{tabular}{|c|c|c|c|c|c|c|}
\hline Parameter & $\begin{array}{l}\text { IUGR A } \\
n=23\end{array}$ & $\begin{array}{l}\text { IUGR B } \\
n=15\end{array}$ & $p$ value & $\begin{array}{c}\text { IUGR } \\
n=38\end{array}$ & $\begin{array}{c}\text { Control group } \\
\qquad n=18\end{array}$ & $p$ value \\
\hline \multicolumn{7}{|l|}{ Maternal characteristic } \\
\hline Age (years) & $29.26 \pm 5.64$ & $30.87 \pm 5.13$ & 0.381 & $29.89 \pm 5.44$ & $29.81 \pm 3.22$ & 0.952 \\
\hline Height (cm) & $162.00 \pm 5.69$ & $161.07 \pm 4.38$ & 0.813 & $161.63 \pm 5.17$ & $162.44 \pm 3.33$ & 0.609 \\
\hline Weight (kg) & $78.08+15.01$ & $76.00 \pm 11.61$ & 0.652 & $77.26 \pm 13.64$ & $76.67 \pm 12.95$ & 0.877 \\
\hline $\operatorname{BMI}\left(\mathrm{kg} / \mathrm{m}^{2}\right)$ & $29.38 \pm 4.94$ & $29.72 \pm 5.41$ & 0.848 & $29.59 \pm 5.16$ & $29.40 \pm 4.99$ & 0.713 \\
\hline \multicolumn{7}{|l|}{ Foetal characteristic } \\
\hline Age (weeks) & $34+6$ & $33+6$ & 0.252 & $34+2$ & 34 & 0.9 \\
\hline Weight (g) & $1707.0 \pm 497.5$ & $1910.2 \pm 512.0$ & 0.089 & $1787.3 \pm 506.7$ & $2053.2 \pm 734.9$ & 0.297 \\
\hline Sex-male, $n(\%)$ & $12(52.2)$ & $8(53.3)$ & 0.94 & $20(52.6)$ & $14(77.8)$ & 0.04 \\
\hline Preeclampsia, $n$ (\%) & $4(17.4)$ & $1(6.7)$ & 0.041 & $5(13.2)$ & 0 & 0.002 \\
\hline $\mathrm{HC}<5 \%, n(\%)$ & $13(56.5)$ & $2(13.3)$ & $>0.0001$ & $15(39.0)$ & 0 & $>0.0001$ \\
\hline \multicolumn{7}{|l|}{ Perinatal outcome } \\
\hline Birth weight (g) & $2198.5 \pm 558.8$ & $2604.2 \pm 386.8$ & 0.017 & $2365.5 \pm 529.3$ & $3018.8 \pm 664.8$ & 0.001 \\
\hline GA at birth (weeks) & $36+6$ & $37+1$ & 0.472 & 37 & $37+4$ & 0.487 \\
\hline$\underline{\text { NICU admission, } n(\%)}$ & $7(35.0)$ & $3(21.4)$ & 0.06 & $10(29.4)$ & $4(22.2)$ & 0.32 \\
\hline Intrauterine still birth, $n(\%)$ & $1(5.2)$ & 0 & 1 & $1(3.1)$ & 0 & 1 \\
\hline
\end{tabular}

GA - gestational age, IUGR - intrauterine growth restricted, NICU - neonatal intensive care unit

cally measured average signal intensity was recorded as the ADC value. The average of ADC values $\left(10-30 \mathrm{~mm}^{2} / \mathrm{s}\right)$ in each hemisphere were compared within each group of IUGR cases and with the control group.

\section{Follow-up of Intrauterine growth restriction cases}

All foetuses had at least one scan within one week of delivery. Follow-up postnatal data were prospectively collected throughout the study with a questionnaire by phone.

\section{Statistical analysis}

Data were analysed using SPSS software, version 22 (IBM Corp., Armonk, NY, USA). Descriptive statistics were assessed. In the data analysis, first the normal distribution of quantitative data was investigated using the KolmogorovSmirnov test of a K-S sample. Regarding the distribution of data (normal and abnormal), Fisher's, chi-square, and T-tests were used at the significance level of less than 0.05 . $\mathrm{ADC}$ values are also presented as mean with standard deviation.

\section{Results}

\section{Population study characteristics}

A total of 38 foetuses with IUGR and 18 of the control group with nearly similar gestational age (approximately
34 weeks) were investigated. IUGR foetuses included 23 with clinical severity signs (group A) and 15 without clinical severity signs (group B).

There was no significant difference between IUGR foetuses and the control group regarding maternal age, body mass index (BMI), and foetal gestational age (29.89 \pm 5.44 years in the IUGR group vs. $29.81 \pm 3.22$ years in the control group; $29.59 \pm 5.16 \mathrm{~kg} / \mathrm{m}^{2}$ in the IUGR group vs. $29.4 \pm 4.99 \mathrm{~kg} / \mathrm{m}^{2}$ in the control group, and 34 weeks +2 days in the IUGR group vs. 34 weeks in the control group respectively). Foetal weight was lower in IUGR cases compared to the control group $(1787.3 \pm 506.7 \mathrm{~g}$ vs. $2053.2 \pm 734.96 \mathrm{~g}$, respectively), but the difference was not significant $(p=0.1)$. There was no significant difference in foetal sex between two groups of IUGR. However, the number of male foetuses was significantly higher in the control than in the IUGR group ( $77 \%$ vs. $52 \%, p=0.04)$. Considering the history of preeclampsia, there was a significant difference between the IUGR and control group and between IUGR subtypes (13.2\% in IUGR foetuses vs. $0 \%$ in the control group, and $17.4 \%$ in IUGR A vs. $6.7 \%$ in IUGR B; $p=0.002$ and 0.04 , respectively). $\mathrm{HC}<5 \%$ was more common in IUGR A compared to IUGR B (56.5\% vs. $13.3 \%, p<0.0001$ ) (Table 1 ).

\section{Doppler study results}

In IUGR group A compared to the other subtype, the UA PI and UtA PI were higher and MCA PI was lower, but 
the differences were not significant (Table 2). Ten (43\%) foetuses in IUGR group A had UA PI $>95^{\text {th }}$ centile, four $(17 \%)$ foetuses had MCA PI $<5^{\text {th }}$ centile and abnormal cerebroplacental ratio (brain sparing), and five (21\%) had UtA PI $>95^{\text {th }}$ centile. There were no foetuses with absent or reversed diastolic flow in the umbilical artery or abnormal flow in ductus venosus in group A (no IUGR cases had severe hypoxia).

\section{Magnetic resonance imaging examination}

\section{Conventional sequences}

Brain white matter and grey matter signal and morphology were normal in all foetuses and no haemorrhagic event like intraventricular or germinal matrix haemorrhage was found in any cases.

\section{Diffusion-weighted magnetic resonance imaging sequences}

In all o the lowest ADC values were detected in the pons, followed by RC, HC, cerebellum, and thalami and the highest ADC values were detected in FWM, OWM, and TWM.

In a comparison between IUGR foetuses and the normal group, the $\mathrm{ADC}$ values were significantly lower in $\mathrm{CH}$ $\left(1.239 \pm 0.164\right.$ vs. $\left.1.280 \pm 0.188 \times 10^{-3} \mathrm{~mm}^{2} / \mathrm{s}, p=0.045\right)$, thalami $\left(1.205 \pm 0.170\right.$ vs. $1.275 \pm 0.158 \times 10^{-3} \mathrm{~mm}^{2} / \mathrm{s}$, $p=0.031)$ and $\mathrm{CN}(1.319 \pm 0.173$ vs. $1.394 \pm 0.166$ $\times 10^{-3} \mathrm{~mm}^{2} / \mathrm{s}, p=0.04$ ) (Figure 2). However, there was no significant difference between them in ADC values of other brain regions. A comparison of ADC values between the two groups is outlined in (Table 3). Among IUGR subtypes, ADC values were not significantly different in any brain region but were slightly lower in HC (1.250 vs. $1.296 \times 10^{-3} \mathrm{~mm}^{2} / \mathrm{sec}$ ), thalami (1.182 vs. 1.239 $\left.\times 10^{-3} \mathrm{~mm}^{2} / \mathrm{s}\right)$, cerebellum $\left(1.228\right.$ vs. $\left.1.257 \times 10^{-3} \mathrm{~mm}^{2} / \mathrm{s}\right)$, RC (1.180 vs. $\left.1.226 \times 10^{-3} \mathrm{~mm}^{2} / \mathrm{s}\right)$, and CN (1.300 vs. 1.348
Table 2. Doppler characteristic in IUGR subtypes

\begin{tabular}{|l|c|c|c|} 
& IUGR A & IUGR B & PValue \\
\hline UA PI & $1.08 \pm 0.41$ & $0.85 \pm 0.18$ & 0.063 \\
\hline MCA PI & $1.65 \pm 0.33$ & $1.78 \pm 0.44$ & 0.411 \\
\hline UtA PI & $1.01 \pm 0.46$ & $0.71 \pm 0.31$ & 0.40 \\
\hline
\end{tabular}

IUGR - intrauterine growth restricted, UA - umbilical artery, MCA - middle cerebral artery, UtA - uterine artery, $\mathrm{PI}$ - pulsatility index

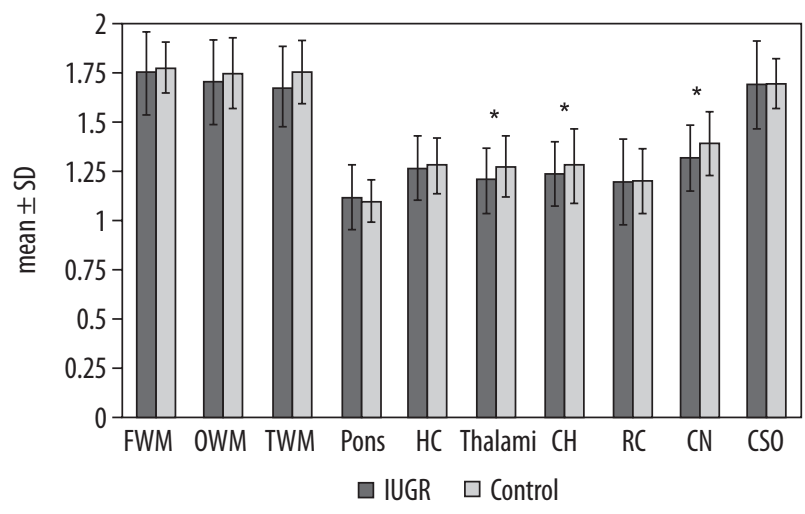

Figure 2. Differences between IUGR foetuses and the control group. The polynomial contrast analysis figure demonstrates the differences between IUGR and non-IUGR foetuses. The bars depict the mean \pm SD within the groups. Asterisks indicate $p<0.05$

$\left.\times 10^{-3} \mathrm{~mm}^{2} / \mathrm{s}\right)$ and were slightly higher in other areas in group A (Table 3.).

\section{Postnatal follow-up}

In the postnatal follow-up, the foetal birth weight was significantly lower in IUGR compared to the control group $(2365.5 \pm 529.3$ g vs. $3018.8 \pm 664.8 \mathrm{~g}, p=0.01)$. Birth weight was also significantly different between IUGR groups A and B $(2198.5 \pm 558.8 \mathrm{~g}$ vs. $2604.2 \pm 386.84 \mathrm{~g}$, $p=0.001)$. There was no significant difference between the two groups and IUGR subtypes regarding gestational age at birth and the rate of NICU admission. Caesarean

Table 3. ADC values in IUGR subtypes, IUGR, and control group in different brain regions

\begin{tabular}{|l|c|c|c|c|c|c|} 
& \multicolumn{1}{|c|}{$\begin{array}{c}\text { IUGR A } \\
n=23\end{array}$} & $\begin{array}{c}\text { IUGR B } \\
n=15\end{array}$ & PValue & $\begin{array}{c}\text { IUGR } \\
n=38\end{array}$ & $\begin{array}{c}\text { Control group } \\
n=18\end{array}$ & $p$ value \\
\hline FWM & $1.750 \pm 0.207$ & $1.746 \pm 0.227$ & 0.958 & $1.748 \pm 0.213$ & $1.774 \pm 0.130$ & 0.568 \\
\hline OWM & $1.724 \pm 0.231$ & $1.708 \pm 0.189$ & 0.442 & $1.706 \pm 0.214$ & $1.750 \pm 0.179$ & 0.190 \\
\hline TWM & $1.707 \pm 0.194$ & $1.670 \pm 0.226$ & 0.307 & $1.679 \pm 0.207$ & $1.753 \pm 0.159$ & 0.156 \\
\hline Pons & $1.119 \pm 0.179$ & $1.116 \pm 0.135$ & 0.952 & $1.118 \pm 0.161$ & $1.100 \pm 0.109$ & 0.32 \\
\hline HC & $1.252 \pm 0.150$ & $1.296 \pm 0.182$ & 0.425 & $1.269 \pm 0.163$ & $1.280 \pm 0.146$ & 0.1 \\
\hline Thalami & $1.182 \pm 0.163$ & $1.239 \pm 0.180$ & 0.316 & $1.205 \pm 0.170$ & $1.275 \pm 0.158$ & 0.031 \\
\hline CH & $1.228 \pm 0.147$ & $1.257 \pm 0.190$ & 0.608 & $1.239 \pm 0.164$ & $1.280 \pm 0.188$ & 0.045 \\
\hline RC & $1.180 \pm 0.205$ & $1.226 \pm 0.238$ & 0.532 & $1.197 \pm 0.216$ & $1.200 \pm 0.162$ & 0.09 \\
\hline CN & $1.300 \pm 0.178$ & $1.348 \pm 0.168$ & 0.412 & $1.319 \pm 0.173$ & $1.394 \pm 0.166$ & 0.04 \\
\hline CSO & $1.703 \pm 0.183$ & $1.676 \pm 0.279$ & 0.747 & $1.693 \pm 0.223$ & $1.699 \pm 0.127$ & 0.422 \\
\hline
\end{tabular}

FWM - frontal white matter, OWM - occipital white matter, TWM - temporal white matter, $\mathrm{CH}$ - cerebellar hemispheres, RC - Rolandic cortex, $\mathrm{CN}$ - caudate nucleus, CSO - centrum semi-ovale 
delivery was more common in the IUGR group ( $83 \%$ vs. $50 \%$ in the control group, $p=0.006$ ). Only one death (stillbirth) in subtype A was reported (Table 1).

\section{Discussion}

DWI is based on proton diffusive motion, and one of its properties is the ability to identify acute or chronic pathologic changes that are not detectable on conventional MR sequences [17]. However, it is still challenging to perform foetal brain DWI due to the motion of both the mother and the foetus [18].

Myelination, ischaemia, and infection are the main processes that decrease ADC values [2]. The DWI sensitivity to detect acute hypoxic-ischaemic events is dependent on its severity and duration, the extent of the affected brain, and the time point of foetal MRI. For example, subtle damage to the brain has no effect on ADC values [17]. Additionally, milder forms of hypoperfusion usually affect periventricular white matter in the premature brain and result in periventricular leukomalacia (PVL) as the most common pathologic finding. In severe hypoperfusion, the most metabolically active brain regions in the immature brain ( $\leq 36$ weeks) include deep grey matter (the thalami and the brainstem), whereas in term infants the vulnerable areas are different and include lateral thalami, hippocampi, and sensorimotor cortex [19,20]. Evidence of mixed acute and chronic hypoxic injuries in histopathological examination of two foetal brains with severe IUGR has been shown by Arthurs et al. [4].

Apart from hypoxia, abnormal maturation is the other proposed mechanism that decreases the ADC values of white matter in IUGR cases. Normal ADC values of cerebral white matter increase gradually up to 30 weeks (possibly related to maximal cellular migration at this time) due to the maturation of brain parenchyma, and subsequently decrease after 30 weeks of gestation. Furthermore, the decline of ADC values in the occipital regions occurs more rapidly after 30 weeks in comparison with frontal lobes due to earlier myelination. Also, brain stem, $\mathrm{CH}$, and thalami ADC values show a linear negative correlation with foetal age. [4,16,21]. However, not all studies suggest this pattern of ADC changes with advancing gestational age [22-24].

Our results indicated that although all cases showed normal brain signals on conventional MRI sequences, IUGR foetuses demonstrated significantly lower ADC values than normal controls in $\mathrm{CH}$, thalami, and $\mathrm{CN}$. The decline in ADC values in thalami and $\mathrm{CN}$ was in accordance with the results of previous studies on ADC values of the foetal brain in IUGR cases. However, in contrast to the previous studies, we found no significant difference between ADC values of FWM or OWM in IUGR foetuses and the control group. [2,4] Considering that the average gestational age of our cases in both groups was about 34 weeks, the decline in ADC value of thalami and $\mathrm{CN}$ are consistent with hypoxia pattern in the immature brain, but RC (or somatosensory cortex) and HC (which, based on the data of previous research, are affected in hypoxic injuries of term infants) showed no significant change in $A D C$ values. However, these findings might also be due to the effects of cerebral blood flow redistribution that alters the normal maturation and myelination.

In contrast to the results of previous research, which insisted on the cerebellum as the most resistant region to hypotension/ hypercarbia $[2,3,25]$, the $\mathrm{ADC}$ values in $\mathrm{CH}$ were relatively low in our study. However, various studies show different findings, and reduced cerebellar area and volume in IUGR foetuses have been shown in some studies $[5,6,10,11]$. The discrepancy between results may be due to the heterogeneity of the IUGR population. Also, based on our results, pons had the lowest ADC value among all groups, and white matter generally had the highest ADC values, which are in agreement with the findings of previous studies $[2,4,26,27]$.

Our DWI findings showed non-significant low ADC values in $\mathrm{CN}, \mathrm{HC}, \mathrm{RC}$, thalami, and $\mathrm{CH}$ in IUGR foetus group A compared to group B. Previous studies indicate that infants with altered umbilical artery Doppler demonstrate significantly poorer motor and cognitive outcomes at around two years of age. Furthermore, decreased MCA PI (brain sparing effect) is associated with worsening hypoxaemia as well as increased incidence of foetal brain injury with subsequently neurological deficits at the age of two years $[6,28,29]$. However, it should be noted that the foetal brain is not spared from injury at any point of time, and brain sparing is a misnomer term. On the other hand, some previous studies suggest that lateonset IUGR foetuses with normal brain Doppler are not really "constitutionally" small, but possibly suffer a form of restriction $[1,30,31]$. The reason that we did not find a significant difference in ADC values of IUGR subtypes might be that Doppler changes were not severe and none of our IUGR cases had severe hypoxaemia-acidosis (no cases with absent or reverse diastolic flow in UA or abnormal flow in DV). Another reason may be related to our relatively small sample size. Also, it can also be related to brain autoregulation as it is trying to protect itself from hypoxia, which results in ADC changes to remain only at a microstructural level.

We had no IUGR cases with IVH even in foetuses with gestational age more than 34 weeks. There is controversy about the correlation between IVH and IUGR in the literature. Several studies considered IUGR as a risk factor for IVH, and other studies suggested a protective role for IUGR. It has been shown that the IVH rate is significantly lower in IUGR cases born $\leq 28$ weeks but is more common in late IUGR (born $\geq 34$ weeks) $[6,32,33]$.

This study has some limitations. First, the sample size was limited, especially to find a significant difference in ADC values between IUGR groups. Second, we had no IUGR cases with severe hypoxia, and we lost two cases 
with severe vascular impairment due to emergent caesarean delivery. The inclusion of cases with severe abnormal Doppler indices might result in a statistically significant difference among the two IUGR groups. Third, we manually placed all ROIs, and that could be subject to inter/ intra-observer variability.

\section{Conclusions}

In our study ADC values of some brain areas (thalami, $\mathrm{CN}$, and $\mathrm{CH}$ ) were significantly lower in IUGR foetuses in comparison with the control group. The ADC values were not significantly different between IUGR subtypes. The mean gestational age of our IUGR foetuses was about 34 weeks, and we detected nearly immature brain hypoxic involvement pattern without significant injuries to RC and HC. Further research with larger sample sizes is needed to evaluate the effect of hypoxia on brain involvement pattern based on ADC values on immature and mature foetal brain ( $\geq 36$ weeks).

\section{Acknowledgments}

We thank all the parents who were willing to participate in the study.

\section{Conflict of interest}

The authors report no conflict of interest.

\section{References}

1. Egaña-Ugrinovic G, Sanz-Cortes M, Figueras F, et al. Differences in cortical development assessed by fetal MRI in late-onset intrauterine growth restriction. Am J Obstet Gynecol 2013; 209: 126.e1-8.

2. Kutuk MS, Sahin M, Gorkem SB, et al. Relationship between Doppler findings and fetal brain apparent diffusion coefficient in earlyonset intra-uterine growth restriction. J Matern Fetal Neonatal Med 2018; 31: 3201-3208.

3. Bruno ChJ, Bengani S, Gomes WA, et al. MRI differences associated with intrauterine growth restriction in preterm infants. Neonatology 2017; 111: 317-323.

4. Arthurs OJ, Rega A, Guimiot F, et al. Diffusion-weighted magnetic resonance imaging of the fetal brain in intrauterine growth restriction. Ultrasound Obstet Gynecol 2017; 50: 79-87.

5. Malhotra A, Ditchfield M, Fahey MC, et al. Detection and assessment of brain injury in the growth restricted fetus and neonate. Pediatr Res 2017; 82: 184-193.

6. Miller SL, Huppi PS, Mallard C. The consequences of fetal growth restriction on brain structure and neurodevelopmental outcome. J Physiol 2016; 594: 807-823.

7. Sanz-Cortés M, Figueras F, Bargalló N, et al. Abnormal brain microstructure and metabolism in small-for-gestational-age term fetuses with normal umbilical artery Doppler. Ultrasound Obstet Gynecol 2010; 36: 159-165.

8. Batalle D, Eixarch E, Figueras F, et al. Altered small-world topology of structural brain networks in infants with intrauterine growth restriction and its association with later neurodevelopmental outcome. Neuroimage 2012; 60: 1352-1366.

9. Tolsa CB, Zimine S, Warfield SK, et al. Early alteration of structural and functional brain development in premature infants born with intrauterine growth restriction. Pediatr Res 2004; 56: 132-138.

10. Padilla N, Falcón C, Sanz-Cortés M, et al. Differential effects of intrauterine growth restriction on brain structure and development in preterm infants: a magnetic resonance imaging study. Brain Res 2011; 1382: 98-108.

11. Polat A, Barlow S, Ber R, et al. Volumetric MRI study of the intrauterine growth restriction fetal brain. Eur Radiol 2017 27: 2110-2118.
12. Link D, Braginsky MB, Joskowicz L, et al. Automatic measurement of fetal brain development from magnetic resonance imaging: new reference data. Fetal Diagn Ther 2018; 43: 113-122.

13. Kiserud T, Piaggio G, Carroli G, et al. The World Health Organization fetal growth charts: a multinational longitudinal study of ultrasound biometric measurements and estimated fetal weight. PLoS Med 2017; 14: e1002220.

14. Ciobanu A, Wright A, Syngelaki A, et al. Fetal Medicine Foundation reference ranges for umbilical artery and middle cerebral artery pulsatility index and cerebroplacental ratio. Ultrasound Obstet Gynecol 2019; 53: 465-472.

15. Bhide A, Acharya G, Bilardo CM, et al. ISUOG practice guidelines: use of Doppler ultrasonography in obstetrics. Ultrasound Obstet Gynecol 2013; 41: 233-239.

16. Sartor A, Arthurs O, Alberti C, et al. Apparent diffusion coefficient measurements of the fetal brain during the third trimester of pregnancy: how reliable are they in clinical practice? Prenat Diagn 2014; 34: 357-66.

17. Kasprian G, Del Río M, Prayer D. Fetal diffusion imaging: pearls and solutions. Top Magn Reson Imaging 2010; 21: 387-394.

18. Han R, Huang L, Sun Z, et al. Assessment of apparent diffusion coefficient of normal fetal brain development from gestational age week 24 up to term age: a preliminary study. Fetal Diagn Ther 2015; 37 : 102-107.

19. Chao ChP, Zaleski ChG, Patton AC. Neonatal hypoxic-ischemic encephalopathy: multimodality imaging findings. Radiographics 2006; 26: S159-72.

20. Gopagondanahalli KR, Li J, Fahey MC, et al. Preterm hypoxicischemic encephalopathy. Front Pediatr 2016; 4: 114.

21. Schneider JF, Confort-Gouny S, Le Fur Y, et al. Diffusion-weighted imaging in normal fetal brain maturation. Eur Radiol 2007; 17: 2422-2429.

22. Cannie M, de Keyzer F, Meersschaert J, et al. A diffusion-weighted template for gestational age-related apparent diffusion coefficient values in the developing fetal brain. Ultrasound Obstet Gynecol 2007; 30: 318-324. 
23. Righini A, Bianchini E, Parazzini C, et al. Apparent diffusion coefficient determination in normal fetal brain: a prenatal MR imaging study. AJNR Am J Neuroradiol 2003; 24: 799-804.

24. Boyer AC, Gonçalves LF, W. Lee, et al. Magnetic resonance diffusion-weighted imaging: reproducibility of regional apparent diffusion coefficients for the normal fetal brain. Ultrasound Obstet Gynecol 2013; 41: 190-197.

25. Sato M, Pawlik G, Heiss WD. Comparative studies of regional CNS blood flow autoregulation and responses to $\mathrm{CO} 2$ in the cat. Effects of altering arterial blood pressure and $\mathrm{PaCO} 2$ on $\mathrm{rCBF}$ of cerebrum, cerebellum, and spinal cord. Stroke 1984; 15: 91-97.

26. Biegon A, Hoffmann Ch. Quantitative magnetic resonance imaging of the fetal brain in utero: Methods and applications. World J Radiol 2014; 6: 523-529.

27. Schneider MM, Berman JI, Baumer FM, et al. Normative apparent diffusion coefficient values in the developing fetal brain. AJNR Am J Neuroradiol 2009; 30: 1799-1803.

28. Spinillo A, Montanari L, Roccio M, et al. Prognostic significance of the interaction between abnormal umbilical and middle cerebral artery Doppler velocimetry in pregnancies complicated by fetal growth restriction. Acta Obstet Gynecol Scand 2009; 88: 159-166.

29. Eixarch E, Batalle D, Illa M, et al. Neonatal neurobehavior and diffusion MRI changes in brain reorganization due to intrauterine growth restriction in a rabbit model. PloS One 2012; 7: e31497.

30. Savchev S, Figueras F, Cruz-Martinez R, et al. Estimated weight centile as a predictor of perinatal outcome in small-for-gestational-age pregnancies with normal fetal and maternal Doppler indices. Ultrasound Obstet Gynecol 2012; 39: 299-303.

31. Crispi F, Figueras F, Cruz-Lemini M, et al. Cardiovascular programming in children born small for gestational age and relationship with prenatal signs of severity. Am J Obstet Gynecol 2012; 207: 121. e1-9.

32. Gilbert WM, Danielsen B. Pregnancy outcomes associated with intrauterine growth restriction. Am J Obstet Gynecol 2003; 188: 1596-1601.

33. Ortigosa Rocha C, Bittar RE, Zugaib M. Neonatal outcomes of late-preterm birth associated or not with intrauterine growth restriction. Obstet Gynecol Int 2010; 2010: 231842. 